\title{
Characteristics and outcomes of gastroduodenal ulcer bleeding: a single-centre experience in Lithuania
}

\author{
Pavel Petrik ${ }^{1}$, Saulė Brašiškienè2, Eglė Petrik ${ }^{3}$ \\ ${ }^{1}$ Clinic of Gastroenterology, Nephro-Urology and Surgery, Centre of General Surgery, Vilnius University, Faculty of Medicine, \\ Vilnius, Lithuania \\ ${ }^{2}$ Clinic of Gastroenterology, Nephro-Urology and Surgery, Centre of Hepatology, Gastroenterology and Dietetics, \\ Faculty of Medicine, Vilnius University, Vilnius, Lithuania \\ ${ }^{3}$ Department of Physiology, Biochemistry, Microbiology, and Laboratory Medicine, Vilnius University, Faculty of Medicine, \\ Vilnius, Lithuania
}

Gastroenterology Rev 2017; 12 (4): 277-285

DOI: https://doi.org/10.5114/pg.2017.72103

Key words: peptic ulcer bleeding, comorbid illnesses.

Address for correspondence: Pavel Petrik MD, Clinic of Gastroenterology, Nephro-Urology and Surgery, Centre of General Surgery,

Vilnius University, Faculty of Medicine, Ciurlionio 21, 03101 Vilnius, Lithuania, phone: +37 060371467, e-mail: petrik.pavelas@gmail.com

\begin{abstract}
Introduction: Despite the optimal use of combined endoscopic haemostasis and pharmacologic control of acid secretion in the stomach, mortality in patients with peptic ulcer bleeding (PUB) has remained constant. Recent data has shown that the majority of patients with PUB die of non-bleeding-related causes.

Aim: To provide an overview of our experience of PUB management, with emphasis on the effect of age, gender, comorbidities, and drug use on the characteristics and outcomes of gastroduodenal ulcer bleeding.

Material and methods: We retrospectively reviewed the medical records of all patients admitted with the primary diagnosis of acute, chronic or unspecified gastric and/or duodenal ulcer with haemorrhage during 2008-2012.

Results: Two hundred and nineteen patients were identified. $46.6 \%$ of patients were $\geq 65$ years old (elderly) and $53.4 \%$ were $<65$ years old (young). The young patients were more likely to have duodenal ulcers and liver failure at admission. Previous use of medications was more regularly observed in gastric ulcer patients than in duodenal ulcer patients. Rebleeding occurred in $43(19.6 \%)$ patients and death in $5(2.3 \%)$ patients. Increased risk of mortality in our patients was associated with age $\geq 65$ years $(\mathrm{RR}=2.21 ; 95 \% \mathrm{Cl}: 1.90-2.56 ; p=0.021)$.

Conclusions: Management of peptic ulcer bleeding should aim at reducing the risk of multiorgan failure and cardiopulmonary death instead of focusing merely on successful haemostasis.
\end{abstract}

\section{Introduction}

Peptic ulcer bleeding (PUB) is one of the most common medical emergencies presenting to hospitals around the world, with both a significant morbidity and a high mortality rate. The estimated annual incidence is about $19-57$ cases per 100,000 people [1]. Peptic ulcer bleeding is responsible for almost half of the cases of upper gastrointestinal bleeding (UGIB) [2, 3].

Around $80-85 \%$ of PUB stops spontaneously and further endoscopic therapy is not required. However, those with recurrent bleeding have 10-fold higher mortality. Rebleeding occurs in as many as $10-30 \%$ of patients after primary endoscopic haemostasis [4]. A recent study has shown that mortality in patients after therapeutic endoscopy is related to patient age, presence of comorbid conditions, haemodynamic instability at admission, intra-hospital bleeding, recurrent bleeding, and need for surgery [5].

Age has been considered as a significant prognostic factor for adverse outcomes from PUB, including rebleeding and mortality $[5,6]$. The risk is increased significantly in individuals aged $\geq 65$ years and increases further in patients aged $>75$ years [7-10]. Unlike in younger patients, the presentation of peptic ulcer disease (PUD) in the elderly is insidious and odd, and therefore diagnosis is delayed.

Current evidence suggests that Helicobacter pylori (HP) infection and non-steroidal anti-inflammatory 
drugs (NSAIDs) increase the risk of PUB. However, the relationship between these two factors in the pathogenesis of PUD is still controversial. The risk of PUB is higher in patients with previous history of NSAIDs use than in patients who present with HP infection [11]. However, the outcome of PUB has not been shown to be negatively influenced by these drugs [12].

Over the last two decades, the optimal use of combined endoscopic haemostasis and the use of effective acid antisecretory drugs, together with eradication therapies against HP, have made progress in preventing recurrence of PUB. However, during the same period, the prescriptions of NSAIDs, oral anticoagulants, antiplatelet drugs, as well as selective serotonin reuptake inhibitors (SSRIs), have increased several-fold, especially among the elderly $[13,14]$.

The mortality rate from peptic ulcer bleeding is reported to be $5-10 \%[2,3]$. Recent data have shown that the majority of PUB patients die of non-bleeding-related causes [4]. Non-gastrointestinal comorbidities have been found to be an independent risk factor for upper gastrointestinal bleeding (UGIB). This could explain why the incidence of UGIB remains high in the elderly population [15]. Mortality arises from comorbid conditions, such as cardiopulmonary illnesses, multiple organ dysfunction syndrome, diabetes, and terminal malignancy, suggesting that improving management for the bleeding peptic ulcers may impact mortality by very little [16].

\section{Aim}

The aim of this study was to provide an overview of our experience of peptic ulcer bleeding management, with emphasis on the effect of age, gender, comorbidities, and drug use on the characteristics and outcomes of gastroduodenal ulcer bleeding.

\section{Material and methods}

This study was a retrospective review of medical records of the patients admitted to the Centre of Hepatology, Gastroenterology, and Dietetics, Vilnius University Hospital "Santariskiu Klinikos", Vilnius, Lithuania from January $1^{\text {st }}, 2008$ to December $31^{\text {st }}, 2012$. The primary study sample was obtained using International Classification of Diseases $10^{\text {th }}$ Version, Clinical Modification (ICD-10-CM) codes, based on discharge diagnosis. All consecutive patients hospitalised with a primary diagnosis of acute gastric and/or duodenal ulcer with haemorrhage (K25.0, K26.0), and chronic or unspecified gastric and/or duodenal ulcer with haemorrhage (K25.4, K26.4) were identified. Within these groups, only patients presenting with signs of Gl bleeding and having a verified gastric and/or duodenal peptic ulcer considered to be the source of bleeding were selected. Also, only the first hospitalisation was included if a patient had recurrent hospitalisations for gastroduodenal PUB during this five-year period. Seventeen patients were excluded: 10 patients because of having non-bleeding gastroduodenal peptic ulcers and 7 patients because of presenting with gastroduodenal PUB repeatedly.

Data on patient age, gender, PUD and UGIB anamnesis, clinical signs of UGIB, haemodynamic state, comorbid illnesses, drug use, requirement for transfusion of blood components (TBC), pharmacological therapy, time to endoscopy, endoscopic therapy, ulcer location, length of hospital stay, and in-hospital mortality were collected and analysed.

Clinical signs of UGIB reviewed included haematemesis, haematochezia, melena, and/or blood loss anaemia (BLA).

Comorbid illnesses analysed were as follows: cardiovascular disease (coronary heart disease, hypertension, cardiac arrhythmia, chronic heart failure and cardiac infarction anamnesis), cerebrovascular disease (haemorrhagic or ischaemic stroke anamnesis), pulmonary disease (bronchitis, chronic obstructive lung disease, bronchial asthma, pneumonia, breath insufficiency and pulmonary hypertension), rheumatologic disease (podagra, rheumatoid arthritis, osteochondropathy, and coxarthrosis), kidney failure (e.g. abnormal serum creatinine value, permanent need of dialysis), liver failure (e.g. abnormal serum bilirubin value, end-stage liver disease), malignant disease, and diabetes mellitus (type 1 and 2).

Drug-use analysis included antiplatelet drugs (aspirin, clopidogrel), oral anticoagulants (warfarin), and NSAIDS.

Endoscopic treatment was given in the form of injection therapy with epinephrine, heat-probe thermocoagulation, argon plasma coagulation, haemostatic clip, sclerotherapy or combination therapy in patients with active bleeding, non-bleeding visible vessels, or adherent clots. Endoscopic grading of ulcer lesions was categorised according to the Forrest classification (Table I) [17]. The exact time of upper Gl endoscopy was determined using individual records of the procedure.

Proton pump inhibitors (PPIs) were administered orally and/or by infusion for $72 \mathrm{~h}$ after endoscopy in patients who required endoscopic therapy.

In order to evaluate patient data, according to the age, all patients were divided into two groups: young - those aged $<65$ years, and elderly - those aged $\geq 65$ years.

\section{Statistical analysis}

Data were summarised using descriptive statistics. Continuous variables were compared using the $t$ test or 
the Mann-Whitney $U$ test and presented as the mean \pm standard deviation. Categorical variables were compared using multivariate analysis, and are presented as number and percentage. $P$-values $<0.05$ were considered statistically significant. Data analysis was performed using SPSS version 20.0.

\section{Results}

\section{Patient characteristics}

During a 5-year period, between January $1^{\text {st }}, 2008$ and December $31^{\text {st }}, 2012$, a total of 219 patients (153 males, 66 females) were identified. The male-female ratio was 2.3 (69.9\% vs. $30.1 \%$, respectively, $p<0.001)$.

The average age was $61.9 \pm 16.3$ years (range: $18-96$ years): male $-58.8 \pm 16.4$ years (range: $18-96$ years), female $-69.3 \pm 13.8$ years (range: $31-94$ years). The age distribution at presentation is shown in Figure 1 . The difference between the number of males and females was significant in patients aged $18-40$ years ( 20 vs. 2 , respectively, $p<0.0001$ ), $41-50$ years ( 23 vs. 4 , respectively, $p<0.0001$ ), 51-60 years (32 vs. 10, respectively, $p<0.0001$ ), and $61-70$ years (40 vs. 13 , respectively, $p<0.0001)$. One hundred and two (46.6\%) patients were at least 65 years old, with a mean age of 75.8 \pm 7.1 years, and $117(53.4 \%)$ patients were < 65 years old, with a mean age of $49.8 \pm 11.8$ years.

The most common symptom on presentation was melena - in 183 (83.6\%) patients, followed by haematemesis - in 78 (35.6\%) patients, and syncope - in 30 (13.7\%) patients. $87.2 \%(n=191)$ of patients presented with BLA, and $89.0 \%(n=170)$ of them required TBC.

Seventy-four (33.8\%) patients had a history of previous PUD, and 40 (18.3\%) patients - history of previous
Table I. Forrest classification

\begin{tabular}{|c|c|c|}
\hline Class & Bleeding activity & Risk of rebleeding (\%) \\
\hline \multirow[t]{2}{*}{ । } & Active bleeding & \\
\hline & Spurting haemorrhage & 90 \\
\hline $\mathrm{Ib}$ & Oozing haemorrhage & 30 \\
\hline \multirow[t]{4}{*}{ II } & $\begin{array}{l}\text { Signs of haemorrhage without } \\
\text { active bleeding }\end{array}$ & \\
\hline & Visible vessel & $50-100$ \\
\hline & Adherent clot & 20 \\
\hline & Haematin on ulcer base & $<5$ \\
\hline III & $\begin{array}{l}\text { Ulcer base with no signs } \\
\text { of bleeding }\end{array}$ & $<5$ \\
\hline
\end{tabular}

UGIB. Two hundred and three (92.7\%) patients presented with extra-hospital GI bleeding, and 16 (7.3\%) patients had bleeding while being hospitalized for other reasons.

The patient demographics and clinical characteristics considering age at presentation are shown in Table II. Patients $\geq 65$ years of age were more likely to have comorbid illnesses (76.5\% vs. $47.0 \%$, respectively, $p<0.001)$, namely cardiovascular diseases (65.7\% vs. $32.5 \%$, respectively, $p<0.001)$. Moreover, they tended to present with previous drug use more frequently than the young ( $47.1 \%$ vs. $25.6 \%$, respectively, $p=0.001$ ), namely oral anticoagulants (warfarin) (20.6\% vs. $4.3 \%$, respectively, $p<0.001)$, and stay longer in hospital (7.4 \pm 3.1 days vs. $6.3 \pm 2.5$ days, respectively, $p=0.014$ ). In contrast, patients $<65$ years old presented with melena ( $91.5 \%$ vs. $74.5 \%$, respectively, $p<0.001)$ and

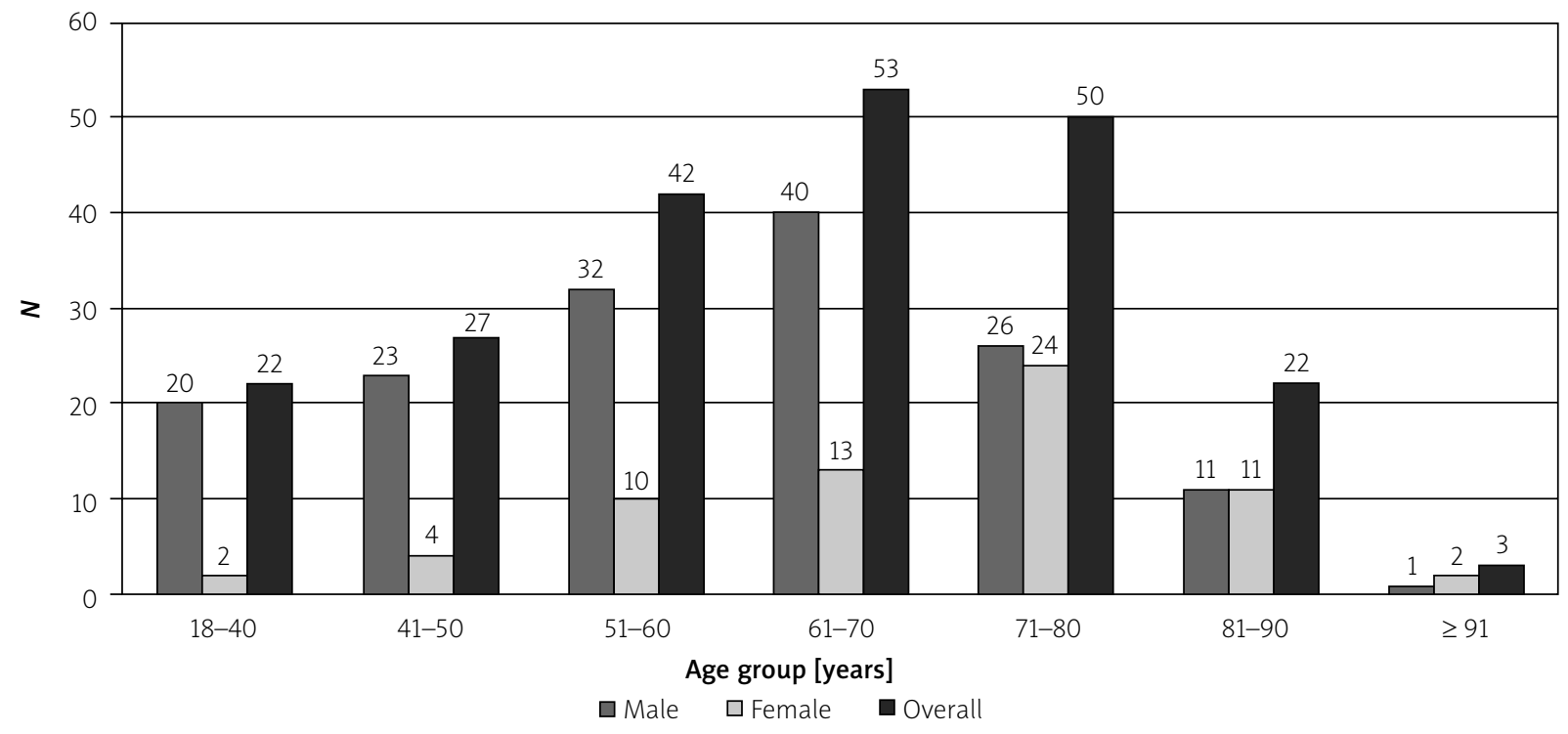

Figure 1. Age distribution of peptic ulcer patients 
Table II. Characteristics of patients according to the age group

\begin{tabular}{|c|c|c|c|c|}
\hline Parameter & $\begin{array}{c}\text { Patients aged } \\
<65 \text { years }(n=117)\end{array}$ & $\begin{array}{c}\text { Patients aged } \\
\geq 65 \text { years }(n=102)\end{array}$ & $P$-value & $\begin{array}{l}\text { Overall } \\
(N=219)\end{array}$ \\
\hline Age [years] & $49.8 \pm 11.8$ & $75.8 \pm 7.1$ & $<0.001$ & $61.9 \pm 16.3$ \\
\hline Male & $94(80.3 \%)$ & $59(57.8 \%)$ & $<0.001$ & $153(69.9 \%)$ \\
\hline \multicolumn{5}{|l|}{ Presenting symptoms: } \\
\hline Haematemesis & $46(39.3 \%)$ & $32(31.4 \%)$ & 0.258 & $78(35.6 \%)$ \\
\hline Haematochezia & $0(0.0 \%)$ & $3(2.9 \%)$ & 0.099 & $3(1.4 \%)$ \\
\hline Melena & 107 (91.5\%) & $76(74.5 \%)$ & $<0.001$ & $183(83.6 \%)$ \\
\hline Blood loss anaemia & $108(92.3 \%)$ & $83(81.4 \%)$ & 0.016 & $191(87.2 \%)$ \\
\hline Haemodynamic instability & $24(23.5 \%)$ & $24(20.5 \%)$ & 0.590 & $48(21.9 \%)$ \\
\hline Syncope & $15(12.8 \%)$ & $15(14.7 \%)$ & 0.686 & $30(13.7 \%)$ \\
\hline \multicolumn{5}{|l|}{ Location of ulcers: } \\
\hline Gastric ulcers & $50(42.7 \%)$ & 55 (53.9\%) & 0.098 & 105 (47.9\%) \\
\hline Duodenal ulcers & $62(53.0 \%)$ & $38(37.3 \%)$ & 0.020 & $100(45.7 \%)$ \\
\hline Gastroduodenal ulcers & $5(4.3 \%)$ & $9(8.8 \%)$ & 0.170 & $14(6.4 \%)$ \\
\hline TBC & $94(80.3 \%)$ & $76(74.5 \%)$ & 0.302 & $170(77.6 \%)$ \\
\hline Comorbid illnesses: & $55(47.0 \%)$ & $78(76.5 \%)$ & $<0.001$ & $133(60.7 \%)$ \\
\hline Cardiovascular disease & $38(32.5 \%)$ & $67(65.7 \%)$ & $<0.001$ & $105(47.9 \%)$ \\
\hline Cerebrovascular disease & $0(0.0 \%)$ & $2(2.0 \%)$ & 0.216 & $2(0.9 \%)$ \\
\hline Pulmonary disease & $4(3.4 \%)$ & $7(6.9 \%)$ & 0.244 & $11(5.0 \%)$ \\
\hline Rheumatologic disease & $5(4.3 \%)$ & $11(10.8 \%)$ & 0.065 & $16(7.3 \%)$ \\
\hline Kidney failure & $4(3.4 \%)$ & $9(8.8 \%)$ & 0.091 & $13(5.9 \%)$ \\
\hline Liver failure & $16(13.7 \%)$ & $3(2.9 \%)$ & 0.005 & $19(8.7 \%)$ \\
\hline Cancer & $5(4.3 \%)$ & $8(7.8 \%)$ & 0.265 & $13(5.9 \%)$ \\
\hline Diabetes mellitus & $11(9.4 \%)$ & $9(8.8 \%)$ & 0.882 & $20(9.1 \%)$ \\
\hline Previous use of medications: & $30(25.6 \%)$ & $48(47.1 \%)$ & 0.001 & $78(35.6 \%)$ \\
\hline NSAID & $16(13.7 \%)$ & $15(14.7 \%)$ & 0.827 & $31(14.2 \%)$ \\
\hline Antiplatelet drugs & $9(7.7 \%)$ & $14(13.7 \%)$ & 0.146 & $23(10.5 \%)$ \\
\hline Oral anticoagulants & $5(4.3 \%)$ & $21(20.6 \%)$ & $<0.001$ & $26(11.9 \%)$ \\
\hline PUD anamnesis & $41(35.0 \%)$ & $33(44.6 \%)$ & 0.675 & $74(33.8 \%)$ \\
\hline UGIB anamnesis & $28(23.9 \%)$ & $12(11.8 \%)$ & 0.020 & $40(18.3 \%)$ \\
\hline Length of stay [days] & $6.3 \pm 2.5$ & $7.4 \pm 3.1$ & 0.014 & $6.8 \pm 2.8$ \\
\hline Mortality & $0(0.0 \%)$ & $5(4.9 \%)$ & 0.021 & $5(2.3 \%)$ \\
\hline
\end{tabular}

anaemia ( $92.3 \%$ vs. $81.4 \%$, respectively, $p=0.016$ ) more commonly than the elderly, and were more likely to have duodenal ulcers (DU) $(53.0 \%$ vs. 37.3\%, respectively, $p=0.020)$ and liver failure at admission (13.7\% vs. $2.9 \%$, respectively, $p<0.005)$. Interestingly, previous history of UGIB was observed more often in this group $(23.9 \%$ vs. $11.8 \%$, respectively, $p<0.020)$. All 5 patients who died were $\geq 65$ years of age ( $4.9 \%$ vs. $0.0 \%$, respectively, $p=0.021$ ). There were no differences in terms of haematemesis, haematochezia, and haemodynamic state at admission, gastric (GU) and gastroduodenal ulcers (GDU), TBC, other comorbid illnesses, use of NSAIDs and antiplatelet drugs, and PUD anamnesis between the two groups. 


\section{Location of ulcers}

One hundred and five (47.9\%) ulcers were located in the stomach, and 100 (45.7\%) - in the duodenum. The GDUs were found in $6.4 \%(n=14)$ of the investigated patients. $63.8 \%(n=67)$ of gastric and $67.0 \%(n=67)$ of duodenal lesions were single. Ulcers were located in all parts of the stomach with a predominance of the prepylorus, lesser curvature, posterior wall, and antrum (Figure 2). Most DUs were located in the duodenal bulb -92 (92.0\%), and only 8 (8.0\%) ulcers were in the postbulbar part of the duodenum.

The DU patients were statistically significantly younger than $\mathrm{GU}$ patients $(57.6 \pm 18.0$ years vs. 65.0 \pm 14.1 years, respectively, $p=0.001)$ and GDU patients $(57.6 \pm 18.0$ years vs. $70.1 \pm 11.2$ years, respectively, $p=0.002)$. Moreover, DUs were more frequently found in males than were GUs $(79.0 \%$ vs. $63.8 \%$, respectively, $p=0.016)$ and GDUs (79.0\% vs. $50.0 \%$, respectively, $p=0.040)$. Furthermore, compared with GU patients, DU patients statistically significantly more frequently presented with melena $(79.0 \%$ vs. $50.0 \%$, respectively, $p=0.040)$, previous history of PUD (41.0\% vs. $24.8 \%$, respectively, $p=0.013)$ and UGIB $(24.0 \%$ vs. $13.3 \%$, respectively, $p=0.049)$, and the average length of stay of DU patients was shorter $(6.3 \pm 2.6$ days vs. $7.2 \pm 2.8$ days, respectively, $p=0.014$ ). However, previous use of medications was more regularly observed in GU patients than in DU patients (44.8\% vs. $27.0 \%$, respectively, $p=0.008)$. Compared with DU patients, death more commonly occurred in GDU patients (14.3\% vs. 2.0\%, respectively, $p=0.019$ )

\section{Comorbidities}

The majority of the patients with no comorbidities were males (79.1\% vs. $63.9 \%$, respectively, $p=0.017)$. In addition, these patients were younger than those with comorbidities $(54.4 \pm 17.7$ years vs. $66.8 \pm 13.3$ years, respectively, $p<0.001)$. As was to be expected, patients with comorbidities were more likely to use drugs than patients with no comorbid conditions ( $46.6 \%$ vs. $18.6 \%$, respectively, $p<0.001)$.

\section{Drug use}

Compared to the patients with drug-use anamnesis, patients with no previous history of drug use were younger $(58.8 \pm 17.4$ years vs. $67.6 \pm 12.6$ years, respectively, $p<0.001)$.

\section{Endoscopic findings}

All ulcers were classified according to the Forrest classification. Active bleeding (Forrest class I) was seen in $34.2 \%(n=75)$, visible vessel (Forrest class IIa), an overly-

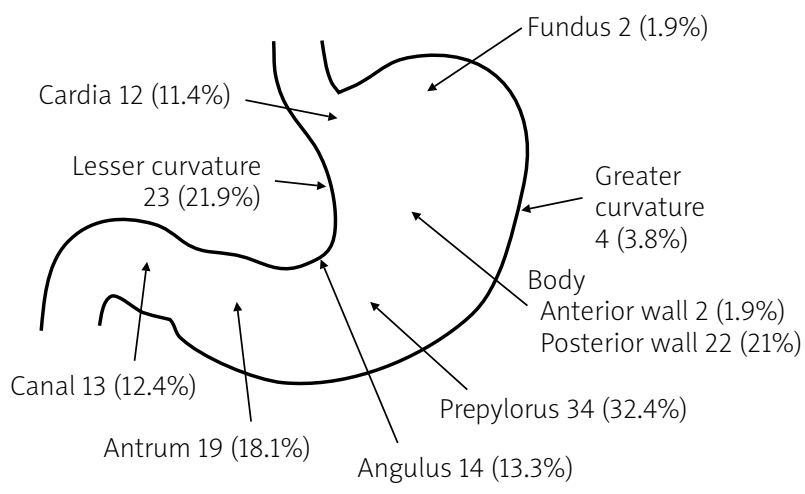

Figure 2. Peptic ulcers of the stomach

ing clot (Forrest class IIb) or haematin-covered base (Forrest class IIc) - in 55.3\% $(n=121)$, and ulcer base with no signs of bleeding (Forrest class III) - in 6.4\% $(n=14)$ of the ulcers. The most frequent classes were $\mathrm{lb}-28.8 \%$ $(n=63)$ of cases and Ila $-27.9 \%(n=61)$ of cases.

Active bleeding was seen in $31.4 \%(n=33)$ of the GUs, $37.0 \%(n=37)$ of the DUs, and $35.7 \%(n=5)$ of the GDUs, as well as in $36.8 \%(n=43)$ of patients aged $<65$ years and in $31.4 \%(n=32)$ of patients aged $\geq 65$ years. Forty-nine (36.8\%) patients with no comorbidities and 26 (30.2\%) patients with comorbid illnesses, $24(30.8 \%)$ patients with drug use anamnesis and 51 (36.2\%) patients with no previous history of drug use presented with signs of spurting or oozing haemorrhage.

Forrest class II was diagnosed in $61.9 \%(n=65)$ of the GUs, $49.0 \%$ ( $n=49)$ of the DUs, and $50.0 \%(n=7)$ of the GDUs, as well as in $51.3 \%(n=60)$ of patients aged $<65$ years and $59.8 \%(n=61)$ of patients aged $\geq 65$ years. Seventy-one (53.4\%) patients with no comorbid illnesses and 50 (58.1\%) patients with comorbid conditions, as well as 45 (57.8\%) patients with drug-use anamnesis and 76 (53.9\%) patients with no drug use anamnesis, presented with signs of recent haemorrhage without active bleeding.

The distribution of ulcer location, patient age, presence of comorbidity, and drug-use anamnesis failed to reach statistically significant different value for various Forrest's classes $(p>0.05)$.

\section{Helicobacter pylori}

Within all patients, Helicobacter pylori (HP) infection was assessed in 156 (71.2\%) patients, with a positive result in $60.9 \%$ of all tested patients. Forty-two (40.0\%) of the tested GU patients, 47 (47.0\%) of the tested DU, and $6(42.9 \%)$ of the tested GDU patients were positive for HP.

\section{Management}

All 219 (100.0\%) patients received PPIs as pharmacological therapy. One hundred and ninety-six (89.5\%) 
patients received endoscopy within $24 \mathrm{~h}$ of admission for UGIB. Within all patients, 181 (82.6\%) patients required endoscopic haemostasis, and haemostasis was achieved successfully during the first upper Gl endoscopy in 155 (85.6\%) patients. In order to provide effective endoscopic haemostasis, 16 (7.3\%) patients required second endoscopy, 5 (2.3\%) patients - third, and 5 (2.3\%) patients - fourth.

The most commonly used endoscopic treatment modality either alone or in combination was epinephrine injection - in 177 (97.8\%) patients. Sclerotherapy was applied in 23 (12.7\%), clipping - in 14 (7.7\%), argon plasma coagulation - in $2(1.1 \%)$, and heat probe thermocoagulation - in $1(0.6 \%)$ patient. Comprehensive data on endoscopic therapy are shown in Table III. Second upper Gl endoscopy was performed in $49.8 \%$ ( $n=109)$ of all patients. However, only 43 (39.4\%) of them required repeated endoscopic treatment due to rebleeding during a hospital stay. Rebleeding occurred in $26.7 \%(n=20)$ of Forrest I ulcers (la -5 (25.0\%), lb $-15(75.0 \%))$ and in $19.0 \%(n=23)$ of Forrest II ulcers (Ila - 14 (60.8\%), Ilb - 7 (30.4\%), Ilc - 2 (8.8\%)). However, no patient with Forrest III ulcer developed recurrent bleeding, as well as none of the patients who needed surgical intervention.

\section{Treatment outcomes}

The mean length of hospital stay was $6.8 \pm 2.8$ days (range: 1-18 days). Rebleeding during a hospital stay occurred in 43 (19.6\%) patients. Among these patients, 17 (16.7\%) patients were $\geq 65$ years of age, 29 (19.0\%) patients were male, and 10 (12.8\%) and 23 (17.3\%) patients presented with previous history of drug use and with comorbid conditions, respectively. We analysed the rebleeding rate according to the age, gender, symptoms on presentation, haemodynamic state at admission, source of bleeding, presence of comorbidities, requirement of TBC, previous history of drug use, PUD and/or UGIB anamnesis, and Forrest class, but the differences were not statistically significant $(p>0.05)$.

Death occurred in 5 (2.3\%) patients: 1 patient died due to cardiopulmonary insufficiency, 1 - due to multiple organ dysfunction syndrome (central nervous system failure, respiratory insufficiency and acute renal failure), 1 - due to acute heart failure, 1 -due to cardiogenic pulmonary oedema, and 1 -due to acute arterial insufficiency. All deaths tended to occur in patients aged $\geq 65$ years old who had comorbid illnesses. By univariate analysis, an increased risk of in-hospital mortality was associated only with age $\geq 65$ years $(\mathrm{RR}=2.21 ; 95 \% \mathrm{Cl}: 1.90-2.56 ; p=0.021)$.

\section{Discussion}

Despite increased knowledge, progressive diagnostics, and new management options, bleeding peptic ulcers still cause a significant clinical problem in the emergency setting. The UGIB is a frequent complication of PUD with a high mortality rate, particularly in elderly people, and even more in patients with comorbid illnesses.

Peptic ulcer bleeding is seen predominantly among the elderly. Men present with ulcer bleeding twice as often as women, except in older age. According to Rockall et al., $68 \%$ of patients are over 60 years of age and $27 \%$ are over 80 years of age [18]. The average age of our patients was $61.9 \pm 16.3$ years, and there was no significant difference in average age between the sexes. Nearly half $(46.6 \%)$ of the patients in our experi-

Table III. Endoscopic treatment of bleeding peptic ulcers

\begin{tabular}{|c|c|c|c|c|c|}
\hline $\begin{array}{l}\text { Epinephrine } \\
\text { injection }\end{array}$ & $\begin{array}{c}\text { Heat probe } \\
\text { thermocoagulation }\end{array}$ & $\begin{array}{l}\text { Argos plasma } \\
\text { coagulation }\end{array}$ & Clipping & Sclerotherapy & $N(\%)$ \\
\hline+ & & & & & $143(79.0)$ \\
\hline+ & & + & & & $1(0.6)$ \\
\hline+ & & + & & + & $1(0.6)$ \\
\hline+ & & & + & & $11(6.0)$ \\
\hline+ & & & + & + & $1(0.6)$ \\
\hline \multirow[t]{4}{*}{+} & & & & + & $20(11.0)$ \\
\hline & + & & & & $1(0.6)$ \\
\hline & & & + & & $2(1.1)$ \\
\hline & & & & + & $1(0.6)$ \\
\hline 177 (97.8\%) & $1(0.6 \%)$ & $2(1.1 \%)$ & $14(7.7 \%)$ & $23(12.7 \%)$ & $181(100.0)$ \\
\hline
\end{tabular}


ence were $\geq 65$ years of age, and the male-female ratio $(2.3: 1)$ was similar to that reported.

The typical clinical presentation of acute UGIB ranges from vomiting of fresh blood or coffee ground-like material ( $40-50 \%$ of cases), melena ( $70-80 \%$ of cases), and passage of blood per rectum (15-20\% of cases) to epigastric pain (41\%) or syncope (14\% of cases) [19]. The most common symptom in our experience was blood loss anaemia $-87.2 \%(n=191)$, followed by melena $-83.6 \%(n=183)$, haematemesis $-35.6 \%(n=78)$, haemodynamic instability $-21.9 \%(n=48)$, and syncope $-13.7 \%(n=30)$, and only $3(1.4 \%)$ patients presented with haematochezia. Interestingly, it has been reported that the incidence of haemodynamic instability as a consequence of UGIB may be underestimated because of the use of $\beta$-blockers, most commonly in the elderly people with comorbid illnesses, especially cardiovascular diseases, thus concealing increased heart rate due to acute blood loss [10]. However, we did not evaluate the use of $\beta$-blockers in our patients.

Our patients $\geq 65$ years of age, compared with patients aged $<65$ years, less commonly presented with melena (74.5\% vs. $91.5 \%$, respectively, $p<0.001)$ and anaemia (81.4\% vs. $92.3 \%$, respectively, $p=0.016)$. Such a difference may be due to the likelihood of the elderly people being often hospitalised for non-life-threatening UGIB in order to provide thorough medical observation due to their putative vulnerability and multiple comorbid illnesses. Consequently, it is thought that the presence of comorbid illnesses may result in the early recognition and/or management of UGIB rather than reflecting the aetiology of the GI bleeding [10]. It is still unclear if the role of age in UGIB is due to a more severe disease or differences in the treatment received. Generally, elderly people are commonly being treated less aggressively than younger patients because of supposition that the risk of any endoscopic procedures is increased due to comorbid conditions. However, Clarke et al. reported upper Gl endoscopy to be extremely safe with satisfactory overall success and morbidity rates, and well tolerated in patients aged as much as 85-94 years [20].

The current study shows that older age is related to the increased incidence of PUB. The main reason that could explain this feature in patients aged $\geq 65$ years is the dramatic increase in prescription of antithrombotic agents (including aspirin, clopidogrel) and NSAIDs in recent years. Nearly half (47.1\%) of our elderly people used either antiplatelet drugs, oral anticoagulants, or NSAIDs. However, only the use of oral anticoagulants was found to be statistically higher (4.8-fold) in the elderly than in the younger patients. Interestingly, Pahor et al. supposed that various manifestations of Gl bleed- ing in elderly people may be explained by ischaemic damage of the GI mucosa [21]. Cardiovascular and cerebrovascular diseases, which were found to be associated with the risk of ulcer bleeding in the aforesaid study, were found in $65.7 \%$ and $2.0 \%$ of our patients aged $\geq 65$ years, respectively.

According to our results, $82.6 \%(n=181)$ of all patients received endoscopic treatment during the first upper Gl endoscopy. The most commonly used endoscopic treatment modality either alone $(79.0 \%)$ or in combination (97.8\%) was epinephrine injection. However, in spite of a large amount of published literature, no single solution for endoscopic injection has been shown to be superior to another in achieving haemostasis. The benefit of combination therapy has been evaluated in many trials and confirmed by meta-analysis. In a systematic review from Spain that aimed to determine whether the addition of a second haemostatic procedure improves haemostatic efficacy and/or patient outcomes after epinephrine injection, a total of 16 randomised studies involving 1.673 patients were analysed [22]. The results have shown the addition of a second procedure to reduce the rate of rebleeding from $18.4 \%$ to $10.6 \%$, and that of emergency surgery from $11.3 \%$ to $7.6 \%$, as well as the mortality rate from $5.1 \%$ to $2.6 \%$.

Haemodynamic instability at admission, endoscopic stigmata of active bleeding, and ulcer size and location were identified as the most consistent prognostic factors for recurrent PUB in patients who received endoscopic therapy [23-26]. Moreover, a recent systematic review by Elmunzer et al. found haemodynamic instability, active bleeding at endoscopy, large ulcer size, lesser gastric curvature ulcer, and posterior duodenal ulcer, as well as comorbid diseases, to be significant prognostic factors for the recurrence of ulcer bleeding [27]. However, in contradistinction to previous studies, we found no statistically significant association between old age, male gender, UGIB symptoms on presentation, haemodynamic state, ulcer location, presence of comorbidities, drug use, requirement for TBC, previous history of PUD and/or UGIB, Forrest class I and II, and the risk of rebleeding.

Recurrent bleeding is one of the most significant predictive factors for mortality [5, 28]. Rebleeding after endoscopic therapy mainly occurs in ulcers showing high-risk stigmata, whereas the risk of recurrent bleeding in patients with ulcer base with no signs of haemorrhage (Forrest class III) is negligible [29]. According to our data, rebleeding occurred in $26.7 \%(n=20)$ of Forrest I ulcers and in $19.0 \%(n=23)$ of Forrest II ulcers. No patient $(0.0 \%)$ with Forrest III ulcers developed recurrent bleeding. Consequently, routine use of second-look endoscopy in all endoscopically treated patients at high risk of rebleeding is proven to be cost-effective [30, 31]. 
Moreover, identified and highly selected patients at low risk of recurrent bleeding could be safely discharged not long after endoscopic therapy.

Despite advances in both pharmacological and endoscopic treatment of patients with bleeding peptic ulcers, mortality remains to be $5-10 \%$ for patients under 60 years of age, $12-25 \%$ for patients over 60 years of age, and almost $35 \%$ in patients over 80 years of age $[32,33]$. As a result of the increasing rates of concomitant comorbidities in the elderly over the last two decades, no significant change in mortality rate has been seen. The mortality rate in our patients was $2.3 \%$, and was lower than those of prior studies.

The majority of patients with peptic ulcer bleeding (nearly $80 \%$ ) die of non-bleeding-related causes [4]. However, the average age of those who die of PUB-related causes is higher than that of those who die of non-PUB-related causes. According to Wong et al., the leading non-bleeding-related causes are multiple organ dysfunction syndrome (23.9\%), pulmonary diseases (23.5\%), and terminal malignancy (33.7\%) [4]. According to our data, death occurred in 5 patients, with a mean age of 83.2 years: 1 patient 80 years old (y.o.) died due to cardiopulmonary insufficiency, 1 (84 y.o.) - due to multiple organ dysfunction syndrome, 1 (85 y.o.) - due to acute heart failure, 1 (82 y.o.) - due to cardiogenic pulmonary oedema, and 1 ( 85 y.o.) - due to acute arterial insufficiency.

The presence of multiple comorbidities, attendant use of antithrombotic and non-steroidal anti-inflammatory drugs, and male gender do not appear to influence the rebleeding rates after endoscopic therapy for bleeding peptic ulcers. Intra-hospital mortality from peptic ulcer bleeding is determined be age $\geq 65$ years and gastroduodenal ulcer bleeding. Management of peptic ulcer bleeding should aim at reducing the risk of multiorgan failure and cardiopulmonary death instead of focusing merely on successful haemostasis.

\section{Conflict of interest}

The authors declare no conflict of interest.

\section{References}

1. Lau JY, Sung J, Hill C, et al. Systematic review of the epidemiology of complicated peptic ulcer disease: incidence, recurrence, risk factors and mortality. Digestion 2011; 84: 102-13.

2. Targownik LE, Nabalamba A. Trends in management and outcomes of acute nonvariceal upper gastrointestinal bleeding 1993-2003. Clin Gastroenterol Hepatol 2006; 12: 1459-66.

3. Barkun A, Sabbah S, Enns R, et al. The Canadian Registry on Nonvariceal Upper Gastrointestinal Bleeding and Endoscopy (RUGBE): endoscopic hemostasis and proton pump inhibition are associated with improved outcomes in a real-life setting. Am J Gastroenterol 2004; 99: 1238-46.
4. Wong SK, Yu LM, Lau JY, et al. Prediction of therapeutic failure after adrenaline injection plus heater probe treatment in patients with bleeding peptic ulcer. Gut 2002; 50: 322-5.

5. Chiu PW, Ng EK, Cheung FK, et al. Predicting mortality in patients with bleeding peptic ulcer after therapeutic endoscopy. Clin Gastroenterol Hepatol 2009; 7: 311-6.

6. Marmo R, Koch M, Cipolletta L, et al. Predictive factors of mortality from nonvariceal upper gastrointestinal hemorrhage: a multicenter study. Am J Gastroenterol 2008; 103: 1639-47.

7. Bardhan KD, Royston C. Time, change and peptic ulcer disease in Rotherham, UK. Dig Liver Dis 2008; 40: 540-6.

8. Sadic J, Borgström A, Manjer J, et al. Bleeding peptic ulcer time trends in incidence, treatment and mortality in Sweden. Aliment Pharmacol Ther 2009; 30: 392-8.

9. Thomopoulos KC, Vagenas KA, Vagianos CE, et al. Changes in aetiology and clinical outcome of acute upper gastrointestinal bleeding during the last 15 years. Eur I Gastroenterol Hepatol 2004; 16: 177-82.

10. Charatcharoenwitthaya P, Pausawasdi N, Laosanguaneak N. Characteristics and outcomes after acute upper gastrointestinal bleeding after therapeutic endoscopy in the elderly. World J Gastroenterol 2011; 17: 3724-32.

11. Kang JM, Kim N, Lee BH, et al. Risk factors for peptic ulcer bleeding in terms of Helicobacter pylori, NSAIDs, and antiplatelet agents. Scand I Gastroenterol 2011; 46: 1295-301.

12. Ljubičić N, Puljiz Z, Budimir I, et al. The influence of etiologic factors on clinical outcome in patients with peptic ulcer bleeding. Dig Dis Sci 2012; 57: 3195-204.

13. Lu Y, Sverdén E, Ljung R, et al. Use of non-steroidal anti-inflammatory drugs and proton pump inhibitors in correlation with incidence, recurrence and death of peptic ulcer bleeding: an ecological study. BMJ Open 2013; 3: e002056.

14. Åhsberg K, Höglund P, Staël von Holstein C. Mortality from peptic ulcer bleeding: the impact of comorbidity and the use of drugs that promote bleeding. Aliment Pharmacol Ther 2010; 32: 801-10.

15. Crooks CJ, West J, Card TR. Co-morbidities affect rsk of nonvariceal upper gastrointestinal bleeding. Gastroenterology 2013; 144: 1384-93.

16. Lanas A. Editorial: Upper GI bleeding-associated mortality: challenges to improving a resistant outcome. Am J Gastroenterol 2010; 105: 90-2.

17. Forrest JA, Finlayson ND, Shearman DJ. Endoscopy in gastrointestinal bleeding. Lancet 1974; 2: 394-7.

18. Rockall TA, Logan RF, Devlin HB, et al. Incidence of and mortality from acute upper gastrointestinal haemorrhage in the United Kingdom. Steering committee and members of the National Audit of Acute Upper Gastrointestinal Haemorrhage. BMJ 1995; 311: 222-6.

19. al-Assi MT, Genta RM, Karttunen TJ, et al. Ulcer site and complications: relation to Helicobacter pylori infection and NSAID use. Endoscopy 1996; 28: 229-33.

20. Clarke GA, Jacobson BC, Hammett RJ, et al. The indications, utilization and safety of gastrointestinal endoscopy in an extremely elderly patient cohort. Endoscopy 2001; 33: 580-4.

21. Pahor M, Guralnik JM, Salive ME, et al. Disability and severe gastrointestinal hemorrhage. A prospective study of community-dwelling older persons. J Am Geriatr Soc 1994; 42: 816-25. 
22. Calvet X, Vergara M, Brullet E, et al. Addition of a second endoscopic treatment following epinephrine injection improves outcome in high-risk bleeding ulcers. Gastroenterology 2004; 126: 441-50.

23. Rockall TA, Logan RF, Devlin HB, et al. Risk assessment after acute upper gastrointestinal haemorrhage. Gut 1996; 38: 318-21.

24. Blatchford O, Davidson LA, Murray WR, et al. Acute upper gastrointestinal haemorrhage in west of Scotland: case ascertainment study. BMJ 1997; 315: 510-4.

25. García-Iglesias P, Villoria A, Suarez D, et al. Meta-analysis: predictors of rebleeding after endoscopic treatment for bleeding peptic ulcer. Aliment Pharmacol Ther 2011; 34: 888-900.

26. Guglielmi A, Ruzzenente A, Sandri M, et al. Risk assessment and prediction of rebleeding in bleeding gastroduodenal ulcer. Endoscopy 2002, 34: 778-86.

27. Elmunzer BJ, Young SD, Inadomi JM, et al. Systematic review of the predictors of recurrent hemorrhage after endoscopic hemostatic therapy for bleeding peptic ulcers. Am J Gastroenterol 2008; 103: 2625-32.

28. Marmo R, Koch M, Cipolletta L, et al. Predicting mortality in non-variceal upper gastrointestinal bleeders: validation of the Italian PNED Score and Prospective Comparison with the Rockall Score. Am J Gastroenterol 2010; 105: 1284-91.

29. Barkun A, Bardou M, Marshall JK. Consensus recommendations for managing patients with nonvariceal upper gastrointestinal bleeding. Ann Intern Med 2003; 139: 843-57.

30. Spiegel BM, Ofman JJ, Woods K, et al. Minimizing recurrent peptic ulcer hemorrhage after endoscopic hemostasis: the cost-effectiveness of competing strategies. Am J Gastroenterol 2003; 98: 86-97.

31. Brullet $E$, Campo $R$, Calvet $X$, et al. A randomized study of the safety of outpatient care for patients with bleeding peptic ulcer treated by endoscopic injection. Gastrointest Endosc 2004; 60: 15-21.

32. Peter DJ, Dougherty JM. Evaluation of the patient with gastrointestinal bleeding: an evidence based approach. Emerg Med Clin North Am 1999; 17: 239-61.

33. Chow LW, Gertsch P, Poon RT, et al. Risk factors for rebleeding and death from peptic ulcer in the very elderly. Br J Surg 1998; 85: 121-4.

Received: 17.11 .2014

Accepted: 29.10 .2016 